\title{
AVALIAÇÃo DE JAZIDAS DE AREIA QUARTZOSA PARA A PRODUÇÃO DE CONCRETOS A BASE DE CIMENTO PORTLAND
}

\author{
Sérgio Trajano Franco Moreiras ${ }^{1}$ \\ Otávio Cristiano Montanher ${ }^{2}$ \\ Camila Baraldi ${ }^{3}$ \\ Dayane Camargo ${ }^{4}$
}

\begin{abstract}
Resumo: Os parâmetros granulométricos das jazidas de areia que exercem maior influência nas propriedades mecânicas do concreto são o módulo de finura e o coeficiente de uniformidade. Areias com elevados valores destes índices tendem a produzir concretos com maior resistência mecânica à compressão. Nesse sentido, o presente trabalho avaliou as propriedades granulométricas de três jazidas comerciais do Rio Paraná na região do município de Alto Paraíso (PR). Para analisar a influência da granulometria na produção de concreto foram confeccionados corpos de prova de $100 \mathrm{~mm}$ de diâmetro por $200 \mathrm{~mm}$ de altura com classe de resistência de $20 \mathrm{MPa}$. A seguir foram determinadas a resistência à compressão e a consistência no estado fresco. As três amostras testadas obtiveram resistência aos 28 dias superior a resistência de dosagem mínima de 26,6 MPa. A amostra 3 em relação com a amostra 1 teve resistência superior em $32 \%$ e em relação com a amostra 2 o aumento foi de $12 \%$. Isso se deve pelo maior coeficiente de uniformidade que aumenta o embricamento entre as partículas, diminui o volume de vazios e, por fim, aumenta a resistência à compressão; e com maior módulo de finura menor é a superfície especifica dos grãos, menor é a área de recobrimento da pasta de cimento e por conseqüência maior a resistência mecânica para uma mesma quantidade de areia.
\end{abstract}

Palavras chave: Granulometria; Barramentos no Rio Paraná; Município de Alto Paraíso (PR); Resistência à compressão; Abatimento do tronco de cone

\section{EVALUATION OF QUARTZ SAND DEPOSITS FOR CONCRETES MADE WITH PORTLAND CEMENT}

Abstract: The uniformity coefficient and the fineness modulus are the two grain size parameters of a sand sample that as a great influnce on the concrete strength. High compressive strength results on sand samples with high uniformity coefficient and with high fineness modulus are found. In these sense, this article evaluated the grain size properties of three commercial deposits of sand at Parana River in the Alto Paraiso city. To evaluate the influence the three sand sample on the concrete properties specimens that are $100 \mathrm{~mm}$ of diameter, $200 \mathrm{~mm}$ of high and class of resistande of $20 \mathrm{MPa}$ were made. A compressive strength test and a slump test were performed to evaluated this influence. The three sand sample have a 28 days compressive strength higher than 26,6 $\mathrm{MPa}$ (minimum dosage strength). The compressive strength of sample 3 is $32 \%$ higher than sample 1 and $12 \%$

\footnotetext{
${ }^{1}$ Engenheiro Civil, Doutor em Geotecnia pela EESC USP em 2014, docente dos programas de pós graduação em engenharia civil (PCV) e em sustentabilidade (PSU). Email: strajano@gmail.com

${ }^{2}$ Formação em Geografia, Doutor em Geografia pela UEM 2016. Email: otaviocmontanher@yahoo.com.br

${ }^{3}$ Formação em Engenharia Civil pela UEM, aluna de Projeto de Iniciação Cientifica. Email: camilabaraldi@hotmail.com

${ }^{4}$ Formação em Engenharia Civil pela UEM, aluna de Projeto de Iniciação Cientifica. Email: dayanejackes@hotmail.com
} 
higher than sample 2 . It begins because sample 3 with higher uniformity coefficient as a most efficient packing arrengement, consequently lower is the air índex as a higher compressive strength. As higher is fineness modulus lower is the grains surface, lower is the cement past amount and consequently higher is the resistance.

Key words: Grain size properties; Parana River Dams; Compressive strength; Slump

\section{EVALUACIÓN DE YACIMIENTOS DE ARENA QUARTZOSA PARA LA PRODUCCIÓN DE HORMGONES A BASE DE CEMENTOS PORTLAND}

Resumen: Los parámetros granulométricos de los yacimientos de arena que ejercen mayor influencia en las propiedades mecánicas del hormigón son el módulo de finura y el coeficiente de uniformidad. Las arenas con altos valores de estos índices tienden a producir hormigones con mayor resistencia mecánica a la compresión. En ese sentido, el presente trabajo evaluó las propiedades granulométricas de tres yacimientos comerciales del Río Paraná en la región del municipio de Alto Paraíso (PR). Para analizar la influencia de la granulometría en la producción de hormigón fueron confeccionados muestras de $100 \mathrm{~mm}$ de diámetro por 200 $\mathrm{mm}$ de altura con clase de resistencia de $20 \mathrm{MPa}$. A continuación se determinaron la resistencia a la compresión y la consistencia en el estado fresco. Las tres muestras probadas obtuvieron resistencia a los 28 días superior a la resistencia de dosificación mínima de 26,6 $\mathrm{MPa}$. La muestra 3 en relación con la muestra 1 tuvo una resistencia superior en un $32 \%$ y en relación con la muestra 2 el aumento fue del 12\%. Esto se debe al mayor coeficiente de uniformidad que aumenta el envoltorio entre las partículas, disminuye el volumen de vacíos y, finalmente, aumenta la resistencia a la compresión; y con mayor módulo de finura menor es la superficie específica de los granos, menor es el área de recubrimiento de la pasta de cemento y por consecuencia mayor la resistencia mecánica para una misma cantidad de arena.

Palabras clave: Granulometría; Embalses en el Río Paraná; Municipio de Alto Paraíso (PR); Resistencia a la compresión; El abatimiento del tronco de cono

\section{INTRODUÇÃO}

O leito do Rio Paraná é umas das principais jazidas de areia quartzosa na região noroeste do Estado do Paraná. Os sedimentos são gerados pelo intemperismo e erosão das formações rochosas nos setores mais altos da bacia e transportados dos locais de origematé os canais fluviais da rede de drenagem. Os sedimentos formam feições de transporte conhecidas como barras fluviais, as quais possuem taxas de movimentação que variam conforme os níveis d'água e a velocidade de fluxo. Essas barras possuem espessurasque variam conforme o segmento do canal. Nas proximidades de Porto Camargo (PR), os depósitos variam entre alguns centímetros, ou mesmo são inexistentesna margem esquerda (PR) e chegam até alguns metros na margem direita (MS).

Durante o transporte dos sedimentos ocorre uma seleção natural em função da granulometria das partículas de maneira que as partículas da fração areia são separadas 
naturalmente das frações mais finas (partículas com diâmetro inferior a 0,15 mm). Estas partículas podem recobrir os grãos de areia prejudicando a aderência entre a areia e a pasta de cimento.

A areia quartzosa é um material inerte, com baixíssimo índice de absorção de água e dureza na escala mohs igual a 7 , sendo considerado um material excelente para agregado miúdo de concretos à base de cimento Portland, devido ao baixo índice de absorção de água e elevada resistência mecânica. No Brasil existem duas classificações granulométricas para areia. A classificação da granulometria da areia para finalidade de matéria prima para concretos segue as diretrizes da norma ABNT NBR 7211:2009. As partículas são classificadas como grossa entre o intervalo de $4,8 \mathrm{~mm}$ e $2,4 \mathrm{~mm}$; como média entre o intervalo de $2,4 \mathrm{~mm}$ e $0,6 \mathrm{~mm}$ e como fina entre $0,6 \mathrm{~mm}$ e $0,15 \mathrm{~mm}$.

Para concretos, uma das tendências na década de 80 era de se empregar areias grossas. Essas amostras tem menor superfície específica do que amostras com menor diâmetro e com isso necessitam de menor quantidade de pasta de cimento para recobrir os grãos de areia. Atualmente a tendência é empregar areias com granulometria mais distribuída (maior coeficiente de uniformidade), pois tem um melhor embricamento dos grãos na matriz cimentícia e melhor recobrimento da pasta de cimento (HELENE e TERZIAN, 1992).

O rio Paraná é uma das principais jazidas de areia da Região Noroeste do Estado do Paraná, porém após a execução do barramento de Porto Primavera (MS) em 1998 foram diagnosticadas diversas alterações no fluxo e no material transportado que pode afetar a granulometria das amostras e por conseqüência afetar a resistência do concreto (SOUZA FILHO, 2009).

Nesse sentido, os objetivos da pesquisa apresentada são avaliar a granulometria das três amostras e avaliar a resistência à mecânica à compressão de cada amostra empregando corpos de prova cilíndricos de $20 \mathrm{~cm}$ de altura por $10 \mathrm{~cm}$ de diâmetro.

\section{2. ÁREA DE ESTUDO}

O trecho do rio Paraná onde foram coletadas as amostras está situado entre os municípios de Marilena e Guaíra e é umas das ultimas áreas livres de represamentos do Alto Rio Paraná, (SANTOS, 2013). A área de extração, o Rio Paraná, constitui um limite natural entre os estados do Paraná e Mato Grosso do Sul, estando nas proximidades do Parque nacional de Ilha Grande (Figura 1). 


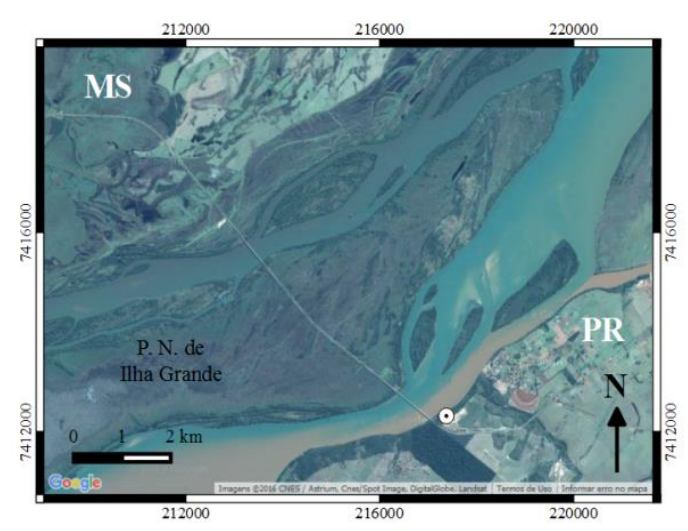

Figura 1: Composição colorida natural de imagem de satélite da área de estudo. A mineradora em questão está representada pelo ponto em branco e preto.

Os leitos fluviais são os ambientes geológicos mais propícios paraa lavra de areia para a construção civil. As feições de acumulação de areia nos leitos fluviais ocorrem principalmente em barras, que podem estar temporariamente emersas e/ou submersas. Dependendo das variações hidrológicas da bacia e do aporte sedimentar, tais barras frequentemente deslocam-se e modificam-se significativamente em escala interanual de tempo.

A mineralogia e a textura das areias de barras fluviais, importantes parâmetros na análise da adequabilidade deste material para uso em concretos,dependem de uma série de fatores, tais como: mineralogia das rochas da área fonte; distância da área fonte; interações entre clima, intemperismo e relevo na bacia hidrográfica. Via de regra, quanto maior a agressividade do intemperismo e a distância da área fonte, maior é a probabilidade de que a assembleia mineralógica das areias de um local seja composta por materiais quimicamente e fisicamente mais resistentes.

Por isso, frequentemente os depósitos de areia de grandes rios (grandes distâncias) são majoritariamente formados por quartzo, como é o caso das areias encontradas no rio Paraná na área de estudo. Também são encontrados minerais pesados, também resistentes ao intemperismo, mas em pequenas proporções. Em relação à textura, em ambientes fluviais lóticos raramente encontram-se frações mais finas (silte e argila) devido à sua manutenção em suspensãona água e transporte à jusante do perfil.

O substrato rochoso é constituído por arenitosda formação Caiuá (Kc) que afloram na margem esquerda e em alguns pontos do leito fluvial. São arenitos formados em ambiente 
eólico, de granulometria média a fina, apresentando boa seleção, possuindo estratificação cruzada de grande porte e coloração arroxeada a avermelhada. A extração de areia na área de estudo é feita por meio de dragagem do leito fluvial, o qual é ligeiramente assimétrico, sendo mais profundo em sua margem esquerda e mais raso em sua margem direita. Esta estrutura produz diferenciações de intensidade de fluxos, os quais são mais intensos nas partes mais profundas. Por sua vez, uma seleção granulométrica natural é produzida pelo rio, em que cascalhos e frações de areia mais grosseira são encontradas nos trechos mais profundos e frações mais finas do material são encontradas nas partes mais rasas. A Figura 2 mostra o descarregamento da draga para o pátio de deposição. Esse processo é realizado por via úmida por intermédio de uma tubulação de diâmetro de $400 \mathrm{~mm}$.

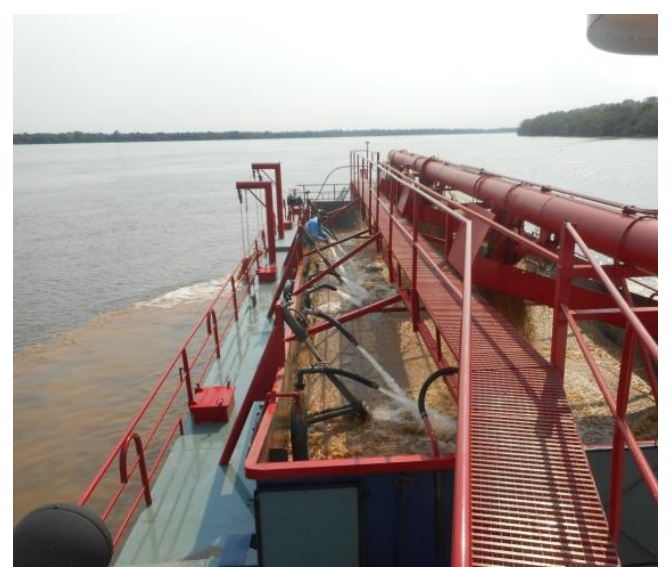

(a)

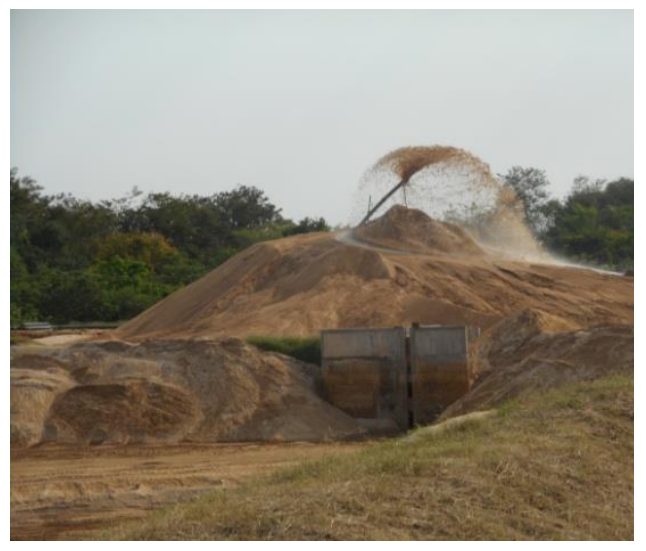

(b)

Figura 2- Processo de extração de areia por dragagem. (a) Vista do carregamento da areia nos tanques da draga. (b) Descarregamento da areia no pátio.

\section{METODOLOGIA}

\subsection{Caracterização das amostras de areia}

Para a pesquisa foram coletadas três amostras de areias no leito do Rio Paraná em área pertencente ao município de Alto Paraíso, próximo ao Porto Figueira. O primeiro lote de amostras foi recolhido de uma jazida comercial de areia fina, o segundo lote de amostras foi recolhido de uma jazida comercial de areia média e o terceiro lote de uma jazida comercial de areia grossa.

A massa específica absoluta das amostras foi determinada segundo as diretrizes da norma ABNT NBR 9776:1988 pelo método do frasco de Chapman. No frasco é inserida uma 
quantidade de água de $200 \mathrm{ml}$. A seguir é adicionada uma massa de aproximadamente $500 \mathrm{~g}$ de areia e determinada a leitura do novo volume (L). A massa especifica absoluta foi determinada pela equação (1).

$$
\rho=\frac{m_{\text {areia }}}{L-200}
$$

A massa especifica aparente foi determinada segundo as diretrizes da norma ABNT NBR NM 45:2006 em uma caixa padrão 15 litros com dimensões de 316 x 316 x 150 mm. Amassa específica aparente da areia foi determinada pela divisão entre a massa de areia contida na caixa pelo volume da caixa.

A curva granulométrica das amostras de areia foi obtida pelo ensaio de peneiramento a partir das porcentagens de areia retida nas peneiras com abertura de 4,8 $\mathrm{mm} ; 2,4 \mathrm{~mm} ; 1,2 \mathrm{~mm}$; 0,6 mm; 0,3 mm e 0,15 mm. A norma ABNT NBR NM 248:2003 traz o procedimento de ensaio e a ABNT 7211:2009 traz os limites de distribuição granulométrica e de módulo de finuras ideais para a confecção de concretos.

A partir da curva foram determinadas as porcentagens de areia fina, média e grossa. Outros parâmetros determinados foram: a dimensão máxima característica, o módulo de finura, o coeficiente de uniformidade e o coeficiente de curvatura.A fração de areia classificada como fina compreende as partículas com diâmetro entre 0,15 e0,60 mm, a classificada como média compreende as partículas com diâmetro entre 0,60 a 2,4 mm e grossa entre 2,4 e $4,8 \mathrm{~mm}$.

A dimensão máxima característica é a dimensão da peneira que apresenta uma porcentagem retida acumulada igual ou imediatamente inferior a 5\% em massa.O módulo de finura é a soma de todas as porcentagens retidasnas peneiras do ensaio de análise granulométrica dividido por 100.A norma ABNT NBR 7211:2009 estabelece que a zona de módulo de finura considerada como ótima para concreto compreende o intervalo entre 2,2 e 2,9 .

O coeficiente de uniformidade $(\mathrm{Cu})$ permite estimar a uniformidade ou não da distribuição dos diâmetros das partículas da amostra. Quanto maior o valor do coeficiente, maior é a distribuição dos valores de diâmetro das partículas. O coeficiente é obtido pela divisão entre o diâmetro correspondente a $60 \%$ das partículas passante e o diâmetro correspondente a $10 \%$ das partículas passantes. 
O coeficiente de curvatura $(\mathrm{Cc})$ permite estimar a continuidade ou não da distribuição do diâmetro das partículas. Areias com coeficiente compreendido entre 1 e 3 são consideradas bem graduadas e, fora deste intervalo, são considerados mal graduadas.A equação (3) calcula o coeficiente de curvatura a partir dos diâmetros $\mathrm{d}_{10}, \mathrm{~d}_{30} \mathrm{e} \mathrm{d}_{60}$ correspondentes à porcentagem de partículas passantes respectivamente de 10,30 e $60 \%$.

$$
C_{c}=\frac{\left(d_{30}\right)^{2}}{d_{60} \times d_{10}}
$$

\subsection{Concreto a base cimento Portland}

Para cada amostra de areia formam confeccionadas 601 de concreto na proporção em massa de 1:2:3:0,5 (cimento:areia:brita:água). A seguir foram avaliadas a resistência à compressão e a consistência do concreto no estado fresco.

\subsubsection{Ensaio de resistência à compressão}

De acordo com a norma ABNT NBR 6118:2014 a resistência mínima de projeto $\left(\mathrm{f}_{\mathrm{ck}}\right)$ para concretos com finalidade estrutural é de $20 \mathrm{MPa}$. Para garantir que essa resistência mínima será atendida durante a confecção do concreto foi determinada a resistência mínima de dosagem $\left(f_{\mathrm{cd}}\right)$ conforme a equação 4.

$$
f_{d}=f_{c k}+1,65 . S_{d}
$$

Foi empregado um valor igual a 4 para o desvio padrão $\left(S_{d}\right)$, que considera a equipe de execução da concretagem bem treinada e os materiais são medidos em volume (HELENE e TERZIAN, 1992). Isso corresponde auma resistênciamínima de dosagem de 26,6 MPa.Para cada amostra de areia foram confeccionados 18 corpos de prova cilíndricos com altura de $200 \mathrm{~mm}$ e diâmetro de $100 \mathrm{~mm}$. Para cada idade de 7, 14 e 28 dias, foram rompidos seis corpos de prova e determinada a média, o desvio padrão e o coeficiente de variação. O ensaio segue o procedimento da norma ABNT NBR 5739:2007, sendo que a taxa de carregamento foi de 0,3 $\mathrm{MPa} / \mathrm{s}$ e a prensa utilizada foi a Emic DL30000N.

\subsubsection{Ensaio de abatimento do tronco de cone}


Para a determinação do abatimento do concreto, empregou-se um molde de forma cônica com diâmetro da base de $200 \mathrm{~mm}$, diâmetro superior de $100 \mathrm{~mm}$ e alturade $300 \mathrm{~mm}$. Após a desmoldagem o abatimento foi determinado pela medida vertical entre o topo do molde posicionado no solo e a parte superior da massa de concreto (ABNT NBR NM 67:1998).

\section{RESULTADOS}

A Figura 3 apresenta as curvas granulométrica das três amostras de areia.

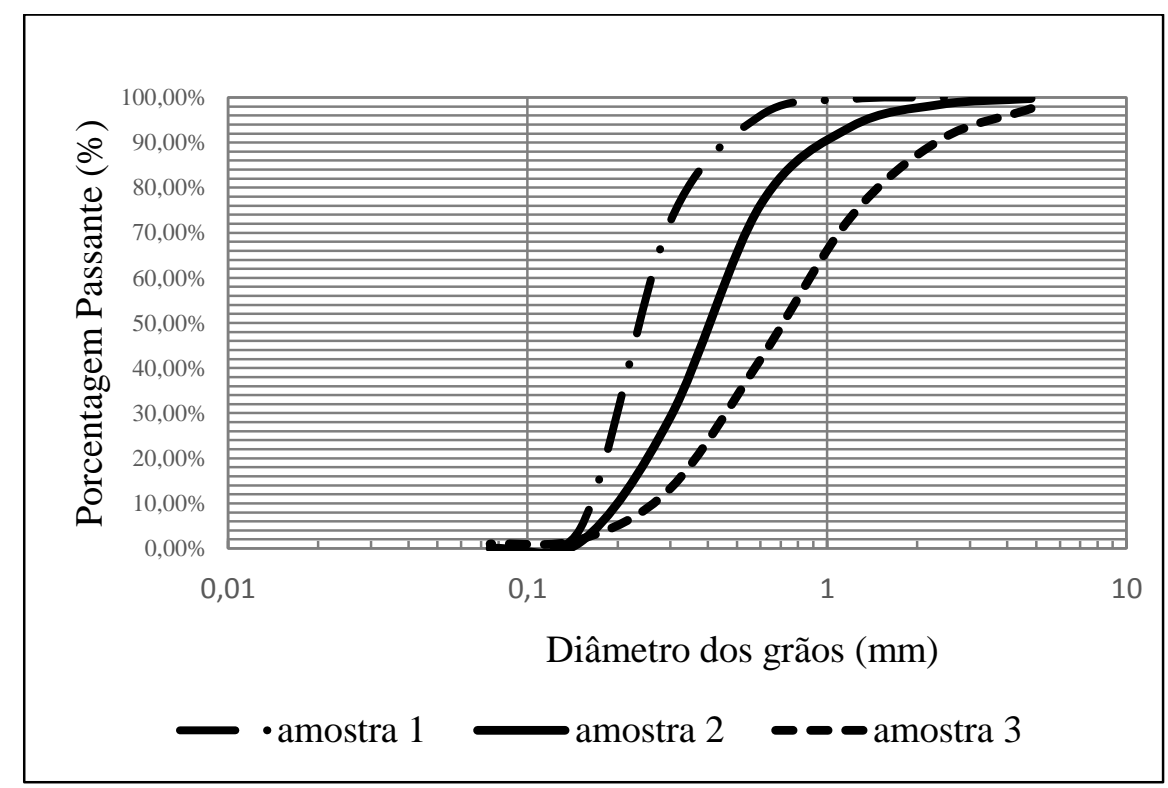

Figura 3 - Curvas granulométricas das três amostras de areia.

A Tabela 1 apresenta a porcentagem de partículas finas, médias e grossas de cada amostra analisada. A Tabela 2 apresenta o módulo de finura, o diâmetro máximo característico, o coeficiente de uniformidade, o coeficiente de curvatura, a massa específica absoluta e a aparente.

Tabela 1. Classificação granulométrica das três amostras

\begin{tabular}{|c|c|c|c|}
\hline Fração & $\begin{array}{c}\text { Amostr } \\
\text { a } 1\end{array}$ & Amostra 2 & Amostra 3 \\
\hline $\begin{array}{c}\text { Grossa }-4,8 \mathrm{~mm} \mathrm{e} \\
2,4 \mathrm{~mm}\end{array}$ & 0,03 & 1,50 & 9,30 \\
\hline
\end{tabular}




\begin{tabular}{|c|c|c|c|}
\hline $\begin{array}{c}\text { Média - 2,4 a 0,6 } \\
\mathrm{mm}\end{array}$ & 1,56 & 22,24 & 48,71 \\
\hline Fina - 0,6 a 0,15 mm & 97,18 & 74,83 & 39,93 \\
\hline Passante \# 0,15 mm & 1,23 & 1,43 & 2,06 \\
\hline
\end{tabular}

A Tabela 2 apresenta o coeficiente de uniformidade, o coeficiente de curvatura,o módulo de finura, o diâmetro máximo característico, a massa específica aparente e a absoluta.

Tabela 2.Parâmetros granulométricos das três amostras

\begin{tabular}{|c|c|c|c|}
\hline Fração & Amostra 1 & Amostra 2 & Amostra 3 \\
\hline $\mathrm{Cu}$ & 1,625 & 2,437 & 3,292 \\
\hline $\mathrm{Cc}$ & 0,868 & 1,088 & 0,944 \\
\hline $\mathrm{MF}$ & 1,24 & 2,02 & 2,84 \\
\hline DMC $(\mathrm{mm})$ & 0,6 & 1,2 & 4,8 \\
\hline m. e. aparente & 1,65 & 1,57 & 1,41 \\
\hline m. e. absoluta & 2,64 & 2,65 & 2,63 \\
\hline
\end{tabular}

A Tabela 3 apresenta os resultados de resistência à compressãoe respectivos desvio padrão e coeficiente de variação aos 7, 14 e 28 dias.

Tabela 3. Resultados de resistência à compressão, desvio padrão e coeficiente de variação aos 7,14 e 28 dias.

\begin{tabular}{|r|r|r|r|r|}
\hline \multirow{1}{*}{$\begin{array}{r}\mathbf{A} \\
\text { mostra }\end{array}$} & $\begin{array}{r}\text { Dias } \\
\text { de ruptura }\end{array}$ & $\begin{array}{c}\text { Tensão } \\
\text { Média (MPa) }\end{array}$ & $\begin{array}{r}\text { Desvio } \\
\text { Padrão (MPa) }\end{array}$ & $\begin{array}{c}\text { Coefic } \\
\text { iente de } \\
\text { Variação (\%) }\end{array}$ \\
\hline \multirow{3}{*}{$\mathbf{1}$} & 7 & 19,56 & 0,9586 & 4,901 \\
\cline { 2 - 5 } & 14 & 23,31 & 0,8349 & 3,582 \\
\hline \multirow{3}{*}{2} & 28 & 28,73 & 2,007 & 6,988 \\
\cline { 2 - 5 } & 7 & 23,26 & 0,9493 & 4,082 \\
\cline { 2 - 5 } & 14 & 29,42 & 0,4757 & 1,617 \\
\hline \multirow{3}{*}{3} & 28 & 33,78 & 0,5234 & 1,55 \\
\cline { 2 - 5 } & 7 & 29,63 & 2,03 & 6,85 \\
\cline { 2 - 5 } & 14 & 36,15 & 2,864 & 7,923 \\
\hline
\end{tabular}


$\mathrm{O}$ fator água cimento empregado das três amostras foi de 0,5 . O abatimento do tronco de cone da amostra 1 e 2 foi de $60 \mathrm{~mm}$ com variação para mais e menos de $10 \mathrm{~mm}$. A amostra 3 teve abatimento de $55 \mathrm{~mm}$ com variação de $10 \mathrm{~mm}$

\section{ANÁLISE DOS RESULTADOS}

\subsection{Resistência à compressão}

As três amostras apresentaram resistência média superior a resistência mínima de dosagem aos 28 dias de 26,6 $\mathrm{MPa}$. Isso demonstra que o traço 1:2:3:0,5 geralmente empregados para areia grossas podem ser empregados para areias médias e finas também. A amostra 3, em relação a amostra 1, obteve resistência superior em $32 \%$. Em relação à amostra 2 o aumento foi de $12 \%$.

A maior resistência à compressão da amostra 3 é justificada pelo maior coeficiente de uniformidade, maior diâmetro médio das partículas e maior modulo de finura do que as amostras 1 e 2. Com maior coeficiente de uniformidade o embricamento entre as partículas é maior, por conseqüência, menor o volume de vazios e, por fim, maior a resistência mecânica à compressão; e quanto maior módulo de finura menor é a superfície especifica dos grãos, menor é a área de recobrimento da pasta de cimento e por conseqüência maior a resistência.

A maior resistência nédia da amostra 2 em relação a amostra1 e justificada devido ao maior coeficiente de uniformidade e pelo maior módulo de finura.

\subsection{Partículas da fração grossa}

A questão da predominância de areais finas nessa região pode estar relacionada ao último represamento do rio Paraná, da UHE de Porto Primavera, em 1998. Este represamento levou a uma série de ajustamentos à jusante, como na hidrologia (SOUZA FILHO, 2009), taxas de erosão marginal e efeitos de piping nas margens (SOUZA FILHO e STEVAUX, 2001), transporte de sedimentos suspensos (MONTANHER e SOUZA FILHO, 2015) e transporte de sedimentos de fundo (SOUZA FILHO, 2007). Este último ocorre devido ao fato de que, após a conclusão do reservatório, o suprimento total de carga de fundo a jusante é cortado. Portanto, a água possui um maior potencial erosivo após sua passagem pela UHE.

$\mathrm{O}$ ajuste da carga de fundo inicia-se com a remoção das frações mais finas, logo abaixo da UHE, que são transportadas mais a jusante. Este processo fez com que houvesse um 
aumento da fração areia fina em Porto São José no período logo após a conclusão de porto primavera (CRISPIM, 2001 apud SOUZA FILHO, 2007). Como esta estação situa-se em um ponto à montante da área de estudo desse trabalho, entende-se que esse processo podeter atingido a região de Porto Camargo, fazendo com que as frações mais grosseiras sejam mais raras.

A taxa de remoção das frações finas desloca-se para jusante em uma velocidade de 10,6 km/ano (SOUZA FILHO, 2008). Como o transporte desses sedimentos pode possuir um alcance ainda maior, justifica-se a hipótese de que o enriquecimento de areias finas em Porto Camargo tenha sido causado pela conclusão da UHE de porto primavera.

\section{CONCLUSÕES}

Este trabalho permitiu concluir que:

- As três amostras de areia quando empregadas no traço 1:2:3:0,5 são viáveis para confeccionar concretos da classe de resistência C 20, ou seja resistência mecânica a compressão característica aos 28 dias de $20 \mathrm{MPa}$.

- Apenas variando as características granulométricas a amostra 1 obteve resistência média de 28,73 MPa, a amostra 2 obteve resistência média de 33,78 MPa e a 3 de 38,07 MPa. Isso mostra a grande influencia da granulometria da amostra de areia na resistência mecânica à compressão dos concretos

- Há uma predominância de areias finas nas jazidas da área de estudo, mesmo em amostras consideradas como pertencentes à fração areia grossa. Isso pode estar ligado às alterações hidrológicas impostas por represamentos à montante da área de estudo.

\section{REFERÊNCIAS}

ASSOCIAÇÃO BRASILEIRA DE NORMAS TÉCNICAS. ABNT NBR NM 248: Agregados - Determinação da composição granulométrica. Rio de Janeiro, 2003.

ABNT NBR 9776: Agregados - Determinação da massa específica de agregados miúdos por meio do frasco Chapman - Método de ensaio. Rio de Janeiro, 1998. unitária. Rio de Janeiro, 2006. ABNT NBR NM 45: Agregado em estado solto - Determinação da massa Janeiro, 2009.

ABNT NBR 7211: Agregados para concreto - Especificação. Rio de . ABNT NBR 5739: Concreto - Ensaios de compressão de corpos-de-prova cilíndricos. Rio de Janeiro, 2007 
de Janeiro, 2014.

ABNT NBR 6118: Projeto de estruturas de concreto - Procedimento. Rio

CRISPIM J. Q. Alterações na hidrologia do canal após construção de reservatório a montante: o caso da Usina Hidrelétrica de Porto Primavera, Rio Paraná. Dissertação de mestrado, Universidade Estadual de Maringá, Pós-graduação em Ecologia de Ambientes Aquáticos Continentais, Maringá, PR, 25p. 2001.

HELENE, P.; TERZIAN, P. Manual de dosagem e controle do concreto. Editora PINI, Brasília 1992.

MONTANHER, O. C.; SOUZA FILHO, E. E. Estimating the suspended sediment concentration in the upper Paraná river using Landsat 5 data: data retrieval on a large temporal scale and analysis of the effects of damming. 2015.

SANTOS, D. N. Análise da extração de areia no trecho livre do canal do alto curso do rio Paraná, entre os municípios de Guaíra e Marilena (PR): impactos ambientais e aplicabilidade. Tese de doutorado, 188 f. 2013. Instituto de Geociências e Ciências Exatas do Campus de Rio Claro, Universidade Estadual Paulista Júlio de Mesquita Filho. Rio Claro, SP, 2013.

SOUZA FILHO, E. E. Evaluation of the Upper Paraná River discharge controlled by reservoirs. Brazilian Journal of Biology. V. 69, n. 2, p. 707-716, 2009.

SOUZA FILHO, E. E. Relatório PELD: Capítulo 1.Meio Físico: Geologia e Geomorfologia. Relatório PELD, 2007.

SOUZA FILHO, E. E. Relatório PELD: Capítulo 1.Meio Físico: Geologia e Geomorfologia. Relatório PELD, 2008.

SOUZA FILHO, E. E.; STEVAUX, J. C. Relatório PELD: Capítulo 1. O componente físico da Planície Alagável do Alto Rio Paraná. Relatório PELD, 2001.

Recebido em 03 de outubro de 2016. Aceito em 21 de novembro de 2017. 